\title{
Bangunan Komersial untuk Pelatihan Terpadu
}

\author{
Haryo Nur Saifullah dan Vincentius Totok Noerwasito \\ Departemen Arsitektur, Fakultas Arsitektur, Desain dan Perencanaan, Institut Teknologi Sepuluh Nopember (ITS) \\ e-mail:vtonoer@arch.its.ac.id
}

\begin{abstract}
Abstrak-Pengangguran adalah salah satu masalah ketenagakerjaan yang dialami oleh setiap kota. Tingkat pengangguran yang tinggi disebabkan antara lain oleh kurangnya keterampilan dan adanya budaya malas pada tenaga kerja. Pembangunan tempat pelatihan vokasi adalah sarana untuk menyalurkan desain yang menjadi solusi dari isyu tersebut. Permasalahan pada desain tempat pelatihan ini adalah bagaimana menghadirkan suasana yang dapat meningkatkan motivasi peserta pelatihan sehingga budaya malas bisa diredam. Dengan metode Inquiry by Design serta pendekatan space and place, tempat pelatihan ini dirancang dengan memperhatikan sirkulasi dan serial vision pengunjung agar terjadi interaksi dengan peserta pelatihan. Deretan vocal point ditata untuk mengajak pengunjung supaya berjalan mendekati dan melihat ke dalam area pelatihan. Change of level diterapkan untuk memberikan kesan terlindungi dan diawasi bagi peserta pelatihan, hal ini adalah upaya untuk mengurangi budaya malas.
\end{abstract}

Kata Kunci-Vokasi, Sirkulasi, Space And Place, Serial Vision, Change of Level.

\section{PENDAHULUAN}

SURABAYA merupakan kota terpadat kedua di Indonesia Syang memiliki potensi pertumbuhan ekonomi dari berbagai sektor (Gambar 1). Seiring dengan potensi tersebut, faktor-faktor penentunya juga perlu bertumbuh secara selaras agar terjadi keseimbangan yang berkesinambungan. Salah satu faktor yang sangat penting dalam pertumbuhan perekonomian di Surabaya tersebut adalah kuantitas dan kualitas tenaga kerjanya [1].

Dari segi kuantitas, pada tahun 2017 masih ada 89.479 orang atau $6,36 \%$ angkatan kerja di Surabaya yang belum memiliki pekerjaan. Sedangkan dari segi kualitas, angkatan kerja yang belum maupun sudah memiliki pekerjaan masih banyak yang kemampuan kerjanya belum terstandarisasi dan diakui melalui sertifikasi. Oleh karenanya, salah satu cara untuk akselesari upaya peningkatan kuantitas dan kualitas tenaga kerja di Surabaya adalah dengan mengadakan program sertifikasi yang terakomodasi pada sebuah tempat pelatihan keprofesian/vokasi.

Fungsi-fungsi utama dari tempat pelatihan tersebut adalah sebagai akomodator dan perangsang pengembangan diri serta memberikan sertifikasi bagi para peserta didiknya. Hal ini akan meningkatkan kesempatan angkatan kerja yang belum memiliki pekerjaan untuk mendapatkan, atau bahkan menciptakan, lapangan pekerjaan. Sedangkan bagi yang sudah memiliki pekerjaan, pelatihan dan sertifikasi tersebut dapat lebih menjamin keberlangsungan karirnya, bahkan meningkatkannya.

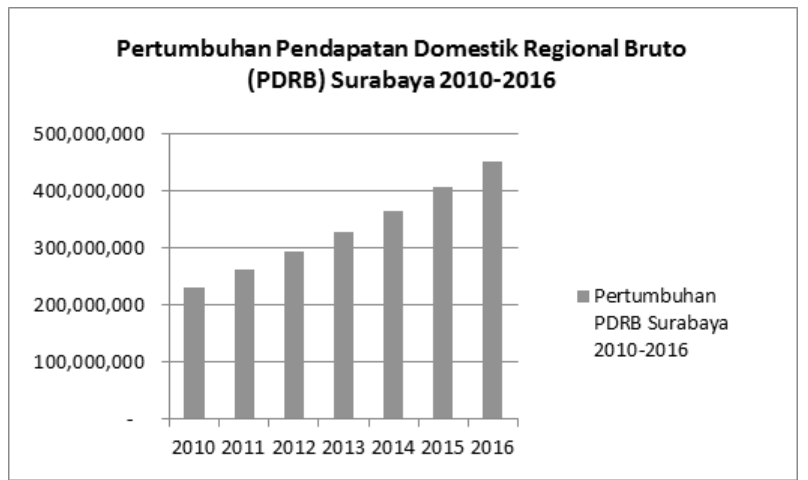

Gambar 1. Pertumbuhan Pendapatan Domestik Regional Bruto (PDRB) Surabaya 2010-2016.

Sumber: BPS Kota Surabaya 2017

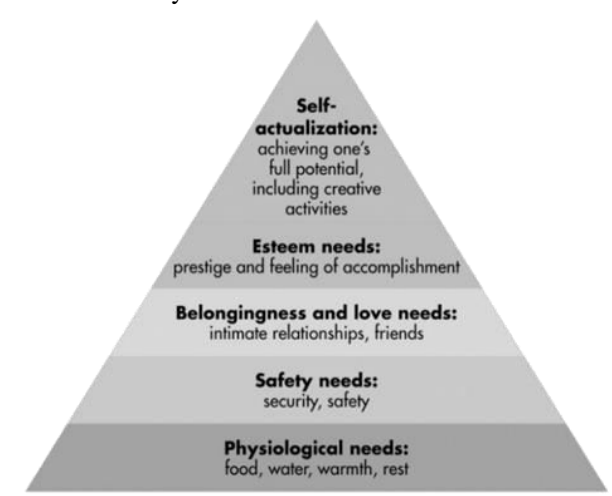

Gambar 2. Piramida hirarki kebutuhan manusia.

Sumber: https://www.simplypsychology.org/maslow.html

Tempat pelatihan ini mempunyai dua bidang, yaitu hospitality dan engineering. Hal ini dikarenakan oleh lapangan pekerjaan utama atau sektor utama yang banyak menyerap tenaga kerja di Kota Surabaya adalah sektor Perdagangan, Rumah Makan, dan Jasa Akomodasi (37,05 persen) dan sektor Industri (17,23 persen).

\section{METODE PERANCANGAN}

Desain "Bangunan Komersial untuk Pelatihan Terpadu" ini ini menjadi solusi adanya permasalahan keterampilan dan etos kerja yang menyebabkan pengangguran bertambah. Desain yang ada bukan hanya berfungsi sebagai wadah pelatihan untuk menempa hard skill, tetapi juga bangunan komersial yang jadi motivasi untuk terus berkarya lebih baik. Interaksi antara peserta pelatihan dengan masyarakat umummya dan pengusaha khususnya dapat meredam budaya malas para pelaku aktivitas pelatihan. 


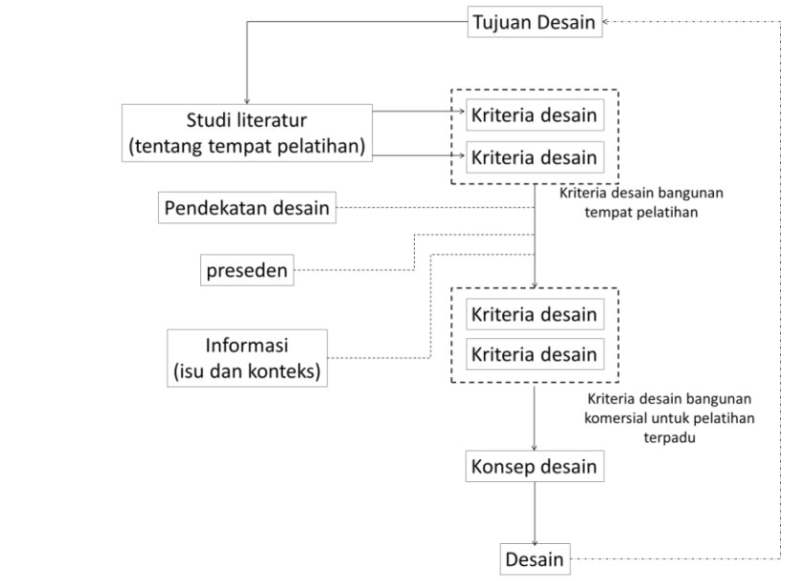

Gambar 3. Adaptasi metode inquiry by design.

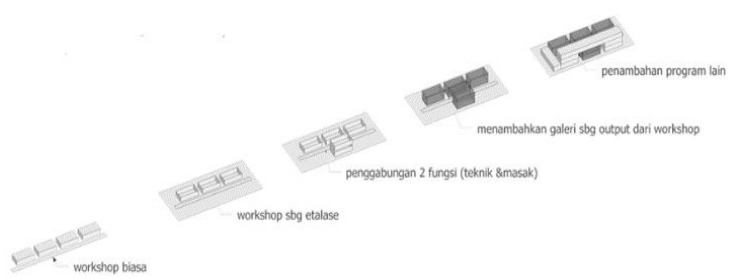

Gambar 4. Diagram bentuk.

Interaksi pada tulisan ini didorong oleh teori hierarki kebutuhan manusia yang dikemukakan Abraham Maslow. Ia menyatakan bahwa manusia memiliki tingkatan kebutuhan yang menjadi prioritas dalam hidupnya untuk dipenuhi. Tingkatan tersebut akan beralih ke tingkat yang lebih tinggi seiring terpenuhinya kebutuhan pada tingkat yang lebih rendah. Dari interaksi yang terjadi, diharapkan timbul motivasi untuk menggapai tingkatan kebutuhan tertinggi yang dikemukakan oleh Maslow, yaitu aktualisasi diri (Gambar 2).

Pendekatan desain yang digunakan adalah pendekatan serial vision. Tujuan dari desain ini salah satunya adalah meningkatkan etos kerja personil tempat pelatihan dengan memberikan tempat tempat interaksi antara peserta pelatihan dengan pengunjung. Untuk itu teori space and place digunakan untuk mendukung pendekatan serial vision.

Teori space and place (ruang dan tempat) mendefinisikan ruang dengan berbagai pola untuk menentukan suasana apa yang dihasilkan. Teori ini menekankan pada sequence dan serial vision.

Hasil rancangan ini memberikan suasana yang mendukung semangat dan motivasi pada setiap aktivitas pelatihan serta pendukungnya. Dalam 46 place yang tertuang dalam buku terjemahan perancangan ruang luar oleh Ir. Sugeng Gunadi, MLA, dirancang berada di beberapa titik dalam rancangan secara keseluruhan [2].

Penulis menggunakan metode Inquiry by Design dari buku yang berjudul sama oleh John Zeisel. Dalam metode tersebut, proses desain berawal dari sebuah image tentang suatu hal, bisa juga disebut ide. Dalam tahap berikutnya, yaitu presensi, ide itu dirancang dan disajikan dengan media tertentu supaya bisa direalisasikan. Sebelum mencapai titik keputusan 'dibangun', rancangan tersebut harus melewati tahap pengujian, tahap ini bisa dilakukan dengan cara menerima feedback dari orang lain atau berpikir kritis secara mandiri. Feedback yang muncul dari

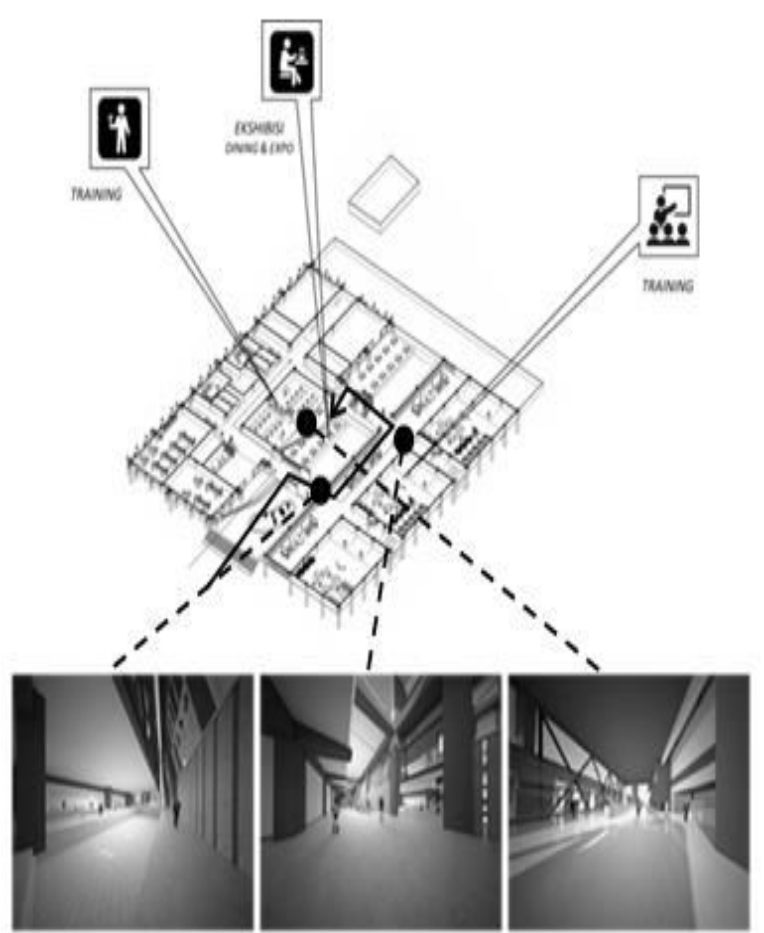

Gambar 5. Konsep sirkulasi dan serial vision pengunjung.

desain akan menghasilkan problem dan solusi baru; kemudian akan disajikan sebagai desain. Rangkaian kegiatan ini terus berulang hingga persetujuan oleh semua pihak terkait pada proyek tercapai. Dalam penerapan pada kasus ini, tahapan dalam metode Inquiry by Design diterjemahkan seperti pada (Gambar 3) [3].

\section{HASIL DAN EKSPLORASI}

\section{Konsep Bentuk}

Bentuk massa mengikuti bentuk ruangan yang ada di dalamya serta dengan bentuk site yang memiliki garis batas sejajar. Bentuk ini juga sesuai dengan tipologi bangunan industry sehingga orang dapat mengenali fungsi bangunan dari melihatnya (Gambar 4). Fasad bangunan diinspirasi oleh motor listrik yang mempunyai sirip-sirip, motor listrik adalah perlambangan dari teknik dan kerja.

\section{Konsep Zoning dan Tatanan Massa}

Objek rancang merupakan sebuah fasilitas yang menampung pelatihan engineering dan hospitality. Dalam konsep pelatihan itu sendiri, terdapat aktivitas pamer karya untuk evaluasi dan pengembangan soft skill bagi peserta pelatihan. Oleh karena itu, diperlukan juga fasilitas ekshibisi diantara kedua fasilitas latihan agar bidang engineering dan hospitality dapat bersinergi dalam pengaplikasian ilmunya.

3. Konsep Sirkulasi

Sirkulasi ditentukan berdasarkan aktivitas dan jenis pengguna. Peserta pelatihan, pelatih, dan pengelola dibuatkan sirkulasi yang pendek untuk memaksimalkan aktivitas pelatihan. Sedangkan pengunjung dibuatkan sirkulasi yang cenderung memaksa mereka untuk melewati ruang pelatihan agar dapat melihat langsung peserta pelatihan serta mendapatkan suasana dari serial vision yang didapat (Gambar $5)$. 


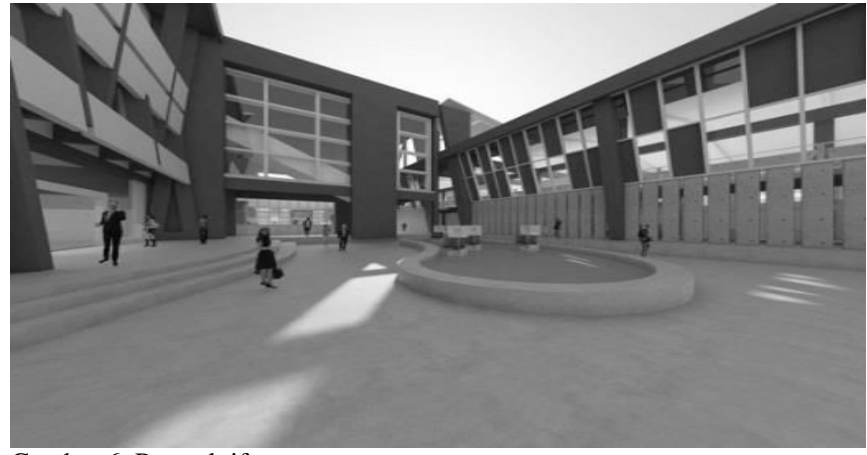

Gambar 6. Perspektif ruang entrance.

\section{Konsep Ruang Luar}

Pengunjung diberi pengalaman sikuen yang menarik dan mengarahkan mereka agar melihat pelatihan yang berlangsung. (Gambar 6) menunjukkan ruang entrance dengan sculpture yang diletakkan di kolam, kemudian disambut oleh view kedalam food court sebagai tujuan. Namun food court tidak bisa langsung diakses, pengunjung harus melewati selasar yang berbatasan dengan area pelatihan. Pengunjung dapat melihat ke dalam area pelatihan dari tempat yang lebih tinggi, hal ini memberi kesan suasana pada pengunjung seakan-akan menguasai apa yang ada di bawah. Secara bersamaan, peserta pelatihan merasa terlindungi dan diawasi sehingga etos kerja dapat terjaga (Gambar 7).

\section{KESIMPULAN}

Tempat pelatihan ini tidak hanya dirancang sebagai fasilitas pelatihan, tetapi juga sebagai bangunan komersil. Hal ini secara fungsi mengundang pengguna eksternal untuk meningkatkan

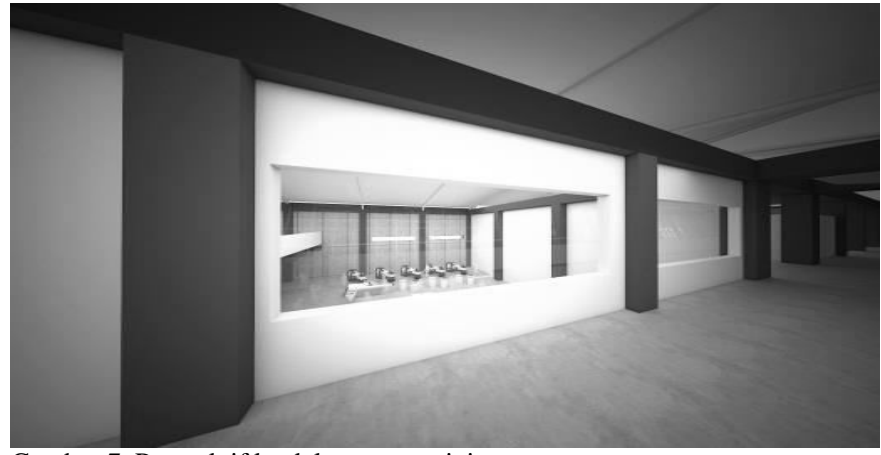

Gambar 7. Perspektif ke dalam area training.

motivasi personil tempat pelatihan. Oleh karena itu, sirkulasi memegang peran penting untuk mempertemukan pengunjung dengan peserta pelatihan.

Deretan vocal point ditata dan diletakkan menjadi sebuah truncation untuk memancing pengunjung datang mendekat. Change of level yang diterapkan pada tempat pelatihan membuat pengunjung merasakan suasana dihormati dan menguasai peserta pelatihan, sedangkan peserta pelatihan dapat merasakan suasana diawasi dan terlindungi sehingga timbul rasa malu untuk bermala-malas.

\section{DAFTAR PUSTAKA}

[1] Badan Pusat Statistik, "Keadaan Ketenagakerjaan Kota Surabaya," Surabaya, 2017.

[2] S. Gunadi, Merancang Ruang Luar. Surabaya: Dian Surya, 1983.

[3] J. Zeisel, Inquiry By Design-Tools for Environment-Behaviour Research. Cambridge: Cambridge University Press, 1981. 